\title{
Closed reduction of zygomatic arch fractures using a Tubbs-Logan mitral valve dilator
}

\author{
Yalçın Yontar1, Sedat Tatar², Halit Baykan³ \\ 1 Department of Plastic Reconstructive and Aesthetic Surgery, Acıbadem Kayseri Hospital, Kayseri, Turkey \\ 2 Department of Plastic Reconstructive and Aesthetic Surgery, Koç University Hospital, Istanbul, Turkey \\ 3 Department of Plastic Reconstructive and Aesthetic Surgery, Kayseri City Training and Research Hospital, Kayseri, Turkey \\ Yalçın Yontar, ORCID: 0000-0002-2598-3248 \\ Sedat Tatar, ORCID: 0000-0002-8051-1497 \\ Halit Baykan, ORCID: 0000-0002-3352-3946
}

\begin{abstract}
Objective: To present technical details and experiences regarding the use of a Tubbs-Logan mitral valve dilator for the closed reduction of zygomatic arch fractures.

Method: Over a period of about three years, closed reduction was indicated and performed in 22 patients with a zygomatic arch fracture. In all patients, depressed fracture segments were reduced using a Tubbs-Logan mitral valve dilator via the Gillies' temporal approach.
\end{abstract}

Results: The majority of the injuries were due to motor vehicle collisions $(n=8,36.4 \%)$. The zygomatic arch fracture was isolated in 12 patients (54.5\%). However, it was a component of a zygomatic complex fracture in 10 patients $(45.5 \%)$. Of those, rigid internal fixation of the zygomatic body was performed in 8 and the zygomatic body was only closely reduced by a bone hook in 2 pa- tients. Repair of a concomitant orbital floor fracture was performed in 2, a mandibular angle fracture in 1 and a frontal sinus fracture in 1 patient. The reduction status of the zygomatic arch was excellent in 12 (54.5\%), good in $8(36.4 \%)$ and fair in 2 patients $(9.1 \%)$. During the follow-ups, no functional or cosmetic sequelae regarding repaired fractures of the zygomatic arch, zygomatic body or other facial bones were recorded.

Conclusion: We suggest that the Tubbs-Logan mitral valve dilator is a safe and effective alternative in terms of closed reduction of zygomatic arch fractures, whether they are isolated or not. We think that further ergonomic modifications would be beneficial to improve the positioning of the instrument in restricted areas observed due to severe depression of the zygomatic arch.

Keywords: Maxillofacial injuries, facial injuries, zygomatic arch, closed fracture reduction.
Correspondence: Yalçın Yontar

Department of Plastic Reconstructive and Aesthetic Surgery, Acıbadem Kayseri Hospital, Kayseri, Turkey

E-mail: dr.yyontar@gmail.com

Received: A; Accepted: A
Online available at: www.entupdatesjournal.org

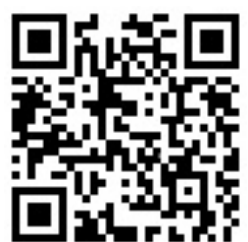




\section{Introduction}

Zygomatic arch fractures are usually encountered as a result of a direct trauma to the malar region and are present in $11 \%$ to $15 \%$ of individuals with other concomitant fractures of the facial bones. ${ }^{[1]}$ As well as other parts of the zygomatic bone, a high incidence of zygomatic arch fractures seems related to the prominent and vulnerable position of the malar complex within the facial skeleton. ${ }^{[2]}$

It is essential to repair a displaced zygomatic arch via an open or closed approach to align midfacial width and projection and to improve impaired mouth movements due to possible impingement of the fracture segments on the coronoid process. Whether open or closed management will be performed primarily depends upon the extent of the injury and whether or not the fracture is severely comminuted. ${ }^{[3]}$ Fortunately, the majority of zygomatic arch fractures are able to be closely reduced. ${ }^{[4-7]}$

We herein intend to present the use of a cardiovascular surgery instrument, the Tubbs-Logan mitral valve dilator, for the closed management of zygomatic arch fractures. It enables anatomical reduction of the fracture segments in an efficient and gradually controlled manner, and thereby we believe that it provides proper bone healing and biomechanical stability.

\section{Materials and Methods}

Between December 2015 and May 2018, 22 patients with a displaced zygomatic arch fracture, in which definitive diagnosis was confirmed radiologically and closed reduction was indicated, were enrolled in the study. The presence of a multifragmented zygomatic arch that could not be stabilized by closed reduction was regarded as an indication for an open approach or splinting; however, except for two cases with multifragmented zygomatic arch, closed reduction alone has resulted in successful treatment in all cases. Local ethics committee approval was obtained, and all patients gave written informed consent before the surgery.

\section{Surgical technique}

All surgical procedures were performed under general anesthesia. According to the Gillies' temporal approach, a temporal scalp incision with a 10 -mm length was performed, and a subcutaneous dissection was carried down to the deep temporalis fascia. A fascial incision was then performed to expose the temporalis muscle, and the subfascial plane was dissected down to the depressed zygomatic arch. The Tubbs-Logan mitral valve dilator was inserted into the dissected subfascial plane and advanced in depth just to the fracture segments. With proper positioning of the instrument, a gradual and constant force was applied to expand its tip, and the fragments were mobilized until acceptable reduction was achieved under direct visualization and non-dominant hand palpation of the fracture site (Figure 1).

\section{Results}

There were 5 female and 17 male patients with a mean age of $39.36 \pm 11.76$ years (range, 18-67 years). The major cause of the injuries was motor vehicle collisions $(n=8$, $36.4 \%)$ followed by assaults $(n=7,31.8 \%)$, falls $(n=3$, $13.6 \%)$, sports-related injuries $(n=3,13.6 \%)$ and work injuries $(n=1,4.5 \%)$.

According to the classification system described by Zingg et al ${ }^{[8]} 12$ patients (54.5\%) had a type A1, 9 (40.9\%) had a type B, and 1 (4.5\%) had a type C zygomatic fracture. Furthermore, regardless of whether the zygomatic arch fracture was a component of a zygomatic complex fracture or not, 6 patients $(27.3 \%)$ had a type IB-V, $5(22.7 \%)$ had a type II-A, 4 (18.2\%) had a type IIB-D, $3(13.6 \%)$ had a type I-B-D, $3(13.6 \%)$ had a type I-A and $1(4.5 \%)$ had a type II-B-R fracture according to the zygomatic arch frac-ture classification system proposed by Ozyazgan et al. ${ }^{[6]}$

The zygomatic arch fractures were all unilateral (left-sided=9, right-sided=13), and were isolated in $12 \mathrm{pa}-$ tients (54.5\%). However, in 10 patients (45.5\%), they were a component of zygomatic complex fracture. Of those, 8 underwent rigid internal fixation of the zygomatic body fracture and 2 with a Zingg et al ${ }^{[8]}$ type $B$ fracture underwent closed reduction by percutaneous usage of a bone hook. In these patients, rigid internal fixation of the zygomatic body fractures was not required due to sufficiently stabilized fracture segments.

Repair of a concomitant orbital floor fracture with porous polyethylene was performed in 2, a mandibular angle fracture in 1 and a frontal sinus fracture in 1 patient. In 2 patients with multifragmented zygomatic arch fracture, internal stabilization was achieved by subfascial insertion of a Foley's catheter for a period of 1 week. The reduction status of the zygomatic arch was excellent in 12 (54.5\%), good in 8 (36.4\%), and fair in 2 patients (9.1\%) according to physical and radiological examinations. ${ }^{[3]}$ Poor reduction was not observed. For at least 6 months of follow-up (mean:15.72 \pm 6.51 , range 6-31 months), no functional or 
cosmetic sequelae regarding repaired fractures of the zygomatic arch, zygomatic body or other facial bones were recorded. Detailed characteristics of the patients are listed in Table 1, and pre- and post-operative computed tomography (CT) scans of two representative cases are presented in Figures 2 and 3.

\section{Discussion}

In clinical practice, the closed reduction of zygomatic arch fractures is frequently performed using specially designed and standardized instruments, such as Rowe's or Gillies' malar elevators. Furthermore, the use of various instruments such as Foley's catheter, ${ }^{[9,10]}$ epistaxis balloon catheter ${ }^{[11]}$ clamps,${ }^{[12,13]}$ screws, ${ }^{[14]}$ wire sutures, ${ }^{[15]}$ bone hooks, ${ }^{[7]}$ etc., have been previously described for this purpose.

In this paper, we present the use of a Tubbs-Logan mitral valve dilator for the closed reduction of zygomatic arch fractures. The instrument came into use in the 1950s to relieve rheumatic mitral valve stenosis. However, it lost its popularity over time as mitral valve replacement surgery replaced mitral valvulotomy. ${ }^{[16,17]}$ The instrument does not require experience to use during zygomatic arch reduction and enables fast employment of the surgical procedure with ease. Its tip has a broad shape and a 5 -mm width when it is closed. By pushing the handle, the tip expands up to 41-mm. Due to the small size of the tip, a smaller skin incision than the classical Gillies' approach is quite enough for comfortable use of the instrument. In addition, it has a shaft length of 166-mm (Figure 1), which is sufficient to reach the zygomatic arch from the temporal incision. Since the opening of the instrument can be adjusted in a gradually controlled manner, it avoids overcorrection of the zygomatic arch. Furthermore, the instrument has sufficient strength to elevate a depressed zygomatic arch, and thus there is no need to apply an outward force, which increases the risk of injury to the temporal bone, especially as during the use of Rowe's malar elevator. We did not experience, however, that the instrument can also be used intra-orally via the Keen approach.

We encountered a technical limitation using the Tubbs-Logan mitral valve dilator during our surgical practice, especially in patients with Ozyazgan et al ${ }^{[6]}$ type I-B-V fractures: if the width of the dissected cleavage medial to the depressed zygomatic arch is less than the closed width of the instrument's tip $(<5-\mathrm{mm})$, its insertion is quite a challenge. In such a situation, the instrument should initially be inserted medial to the relatively wider anterior or posterior part of the $\mathrm{V}$-shaped fracture. By elevating one of these parts, the cleavage is widened and allows the surgeon to advance the instrument for proper correction of the entire zygomatic arch.

\section{Conclusion}

Instead of using standardized elevators, we managed zygomatic arch fractures of 22 patients using a Tubbs-Logan mitral valve dilator, which is no longer widely used in modern cardiovascular surgery. In our opinion, this instrument is a safe and effective alternative in the management of zygomatic arch fractures with satisfactory cosmetic and functional outcomes, whether the fracture is isolated or not. Further ergonomic modifications would be beneficial to improve the positioning of the instrument in restricted areas observed due to severe depression of the zygomatic arch.

\section{Acknowledgement: None}

Ethics Committee Approval: The institutional ethics committee of Koç University approved the study (No: 2019.419.IRB1.068).

Informed Consent: All patients gave written informed consent.

Author Contributions: Designing the study - Y.Y., S.T.; Collecting the data - Y.Y., H.B.; Analyzing the data - Y.Y., H.B.; Writing the manuscript - Y.Y., S.T., H.B.; Confirming the accuracy of the data and the analyses - Y.Y., S.T., H.B.

Conflict of Interest: The authors have no conflicts of interest to declare.

Financial Disclosure: The authors declared that this study had received no financial support. 


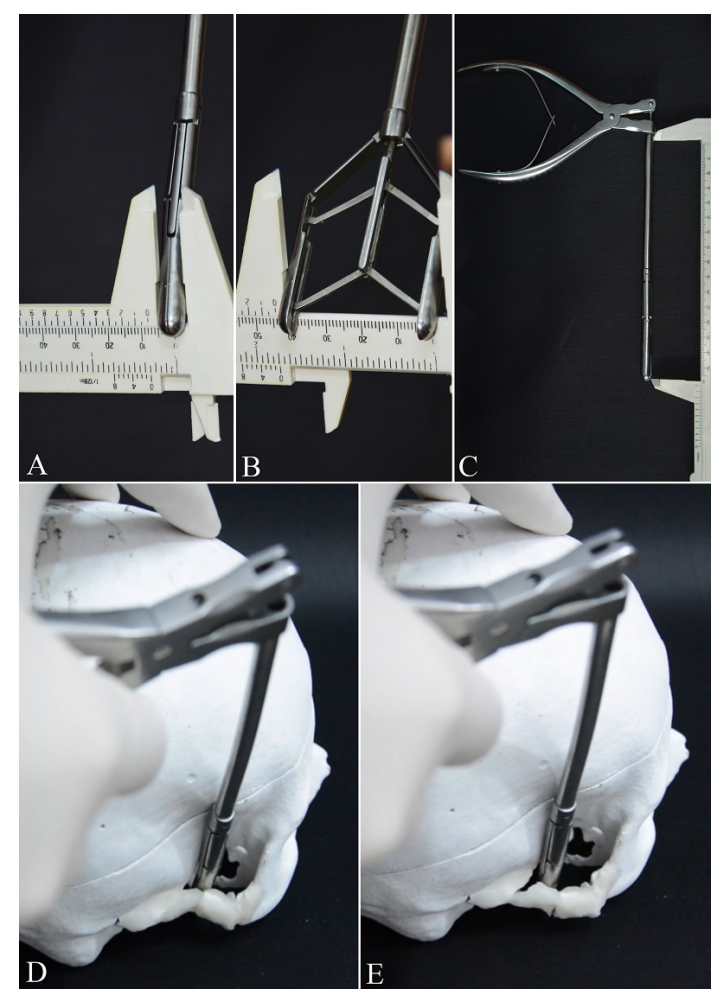

Figure 1. The width of the Tubbs-Logan mitral valve dilator's tip A. closed $(5-\mathrm{mm})$ B. opened $(41-\mathrm{mm})$ C. $161-\mathrm{mm}$ shaft of the instrument. D. Insertion of the dilator and E. mobilized and reduced fracture segments by expanding the tip of the instrument.

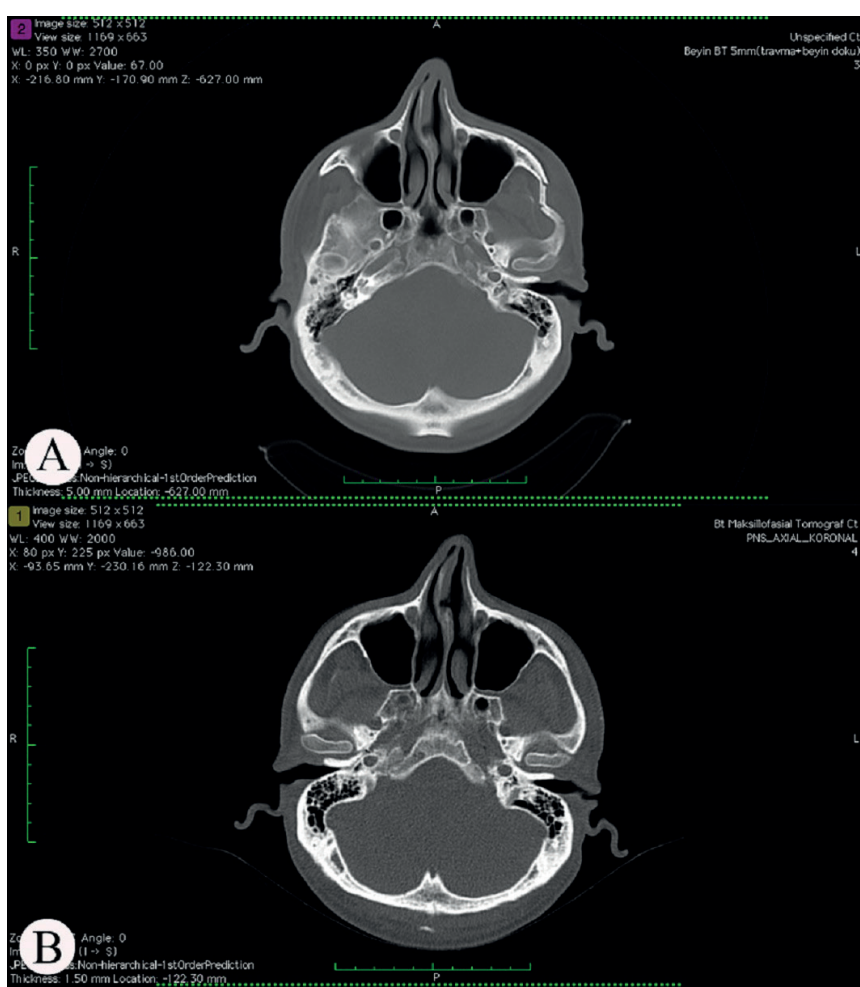

Figure 2. A. Pre-operative B. Early post-operative axial CT scans of Patient 11 with a Zingg et al ${ }^{[8]}$ type A1 and Ozyazgan et al ${ }^{[6]}$ type I-B-V fracture.

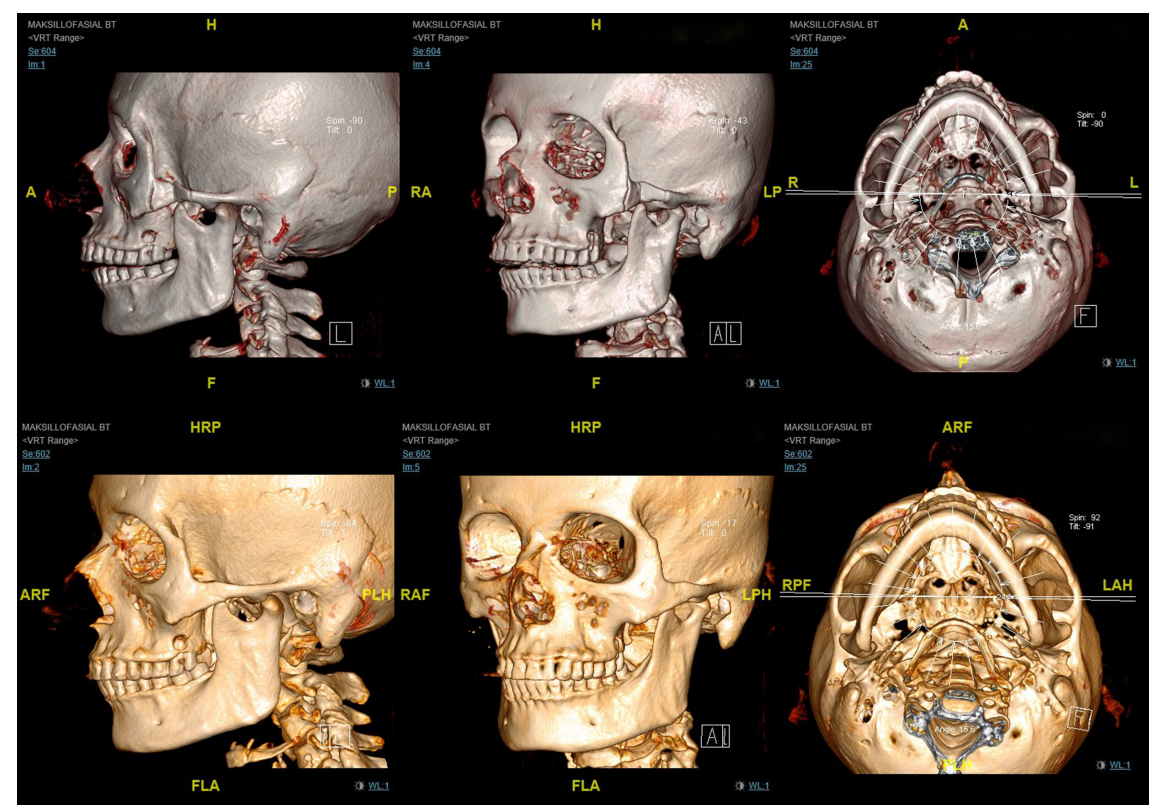

Figure 3. Pre-operative (upper row) and post-operative 3rd month 3D-CT scans (lower row) of Patient 17 with a Zingg et al ${ }^{[8]}$ type $A 1$ and Ozyazgan et al ${ }^{[6]}$ type I-B-V fracture. 


\begin{tabular}{|c|c|c|c|c|c|c|c|c|c|c|}
\hline$\#$ & Gender & Age & Etiology & $\begin{array}{c}\text { Zing et al } \\
\text { classification }{ }^{[8]}\end{array}$ & $\begin{array}{l}\text { Ozyazgan et al } \\
\text { classification }\end{array}$ & $\begin{array}{l}\text { ORIF of } \\
\text { zygomatic } \\
\text { body } \\
\text { fracture }\end{array}$ & $\begin{array}{l}\text { Closed reduction } \\
\text { of zygomatic } \\
\text { body fracture }\end{array}$ & $\begin{array}{l}\text { Internal } \\
\text { splinting }\end{array}$ & $\begin{array}{l}\text { Concomitant } \\
\text { fractures of } \\
\text { the other } \\
\text { facial bones }\end{array}$ & $\begin{array}{l}\text { Reduction } \\
\text { status }\end{array}$ \\
\hline 1 & Male & 20 & MVC & C & II-B-D & + & - & + & $\begin{array}{l}\text { Orbital } \\
\text { floor fracture }\end{array}$ & Good \\
\hline 2 & Female & 55 & Assault & $\mathrm{A} 1$ & I-B-V & - & - & - & - & Excellent \\
\hline 3 & Male & 39 & Fall & $\mathrm{A} 1$ & $1-A$ & - & - & - & - & Excellent \\
\hline 4 & Male & 43 & $\begin{array}{l}\text { Sports- } \\
\text { related } \\
\text { injury }\end{array}$ & A1 & I-B-V & - & - & - & - & Excellent \\
\hline 5 & Female & 36 & MVC & B & II-B-R & + & - & - & $\begin{array}{l}\text { Frontal sinus } \\
\text { anterior wall } \\
\text { fracture }\end{array}$ & Good \\
\hline 6 & Male & 42 & Assault & B & II-A & + & - & - & - & Good \\
\hline 7 & Male & 35 & $\begin{array}{l}\text { Sports- } \\
\text { related } \\
\text { injury }\end{array}$ & $\mathrm{A} 1$ & I-B-V & - & - & - & - & Excellent \\
\hline 8 & Male & 18 & MVC & B & II-B-D & - & + & - & - & Excellent \\
\hline 9 & Female & 45 & MVC & B & II-B-D & + & - & - & - & Good \\
\hline 10 & Male & 35 & Assault & $\mathrm{A} 1$ & I-B-D & - & - & - & - & Excellent \\
\hline 11 & Male & 36 & Assault & A1 & I-B-V & - & - & - & - & Excellent \\
\hline 12 & Male & 42 & MVC & $\mathrm{A} 1$ & I-B-V & - & - & - & - & Excellent \\
\hline 13 & Male & 30 & $\begin{array}{l}\text { Work } \\
\text { injury }\end{array}$ & B & II-A & + & - & - & - & Good \\
\hline 14 & Male & 38 & Assault & B & II-A & - & + & - & $\begin{array}{l}\text { Mandibular } \\
\text { angle fracture }\end{array}$ & Good \\
\hline 15 & Male & 44 & Assault & $\mathrm{A} 1$ & I-A & - & - & - & - & Excellent \\
\hline 16 & Male & 25 & MVC & A1 & I-B-D & - & - & + & - & Fair \\
\hline 17 & Male & 59 & Assault & $\mathrm{A} 1$ & I-B-V & - & - & - & - & Excellent \\
\hline 18 & Female & 26 & MVC & B & II-B-D & + & - & - & $\begin{array}{l}\text { Orbital floor } \\
\text { fracture }\end{array}$ & Excellent \\
\hline 19 & Male & 44 & Fall & B & II-A & + & - & - & - & Good \\
\hline 20 & Female & 41 & Fall & $\mathrm{A} 1$ & I-A & - & - & - & - & Excellent \\
\hline 21 & Male & 67 & MVC & B & II-A & + & - & - & - & Fair \\
\hline 22 & Male & 46 & $\begin{array}{l}\text { Sports- } \\
\text { related } \\
\text { injury }\end{array}$ & A1 & I-B-D & - & - & - & - & Good \\
\hline
\end{tabular}

MVC: Motor vehicle collision

ORIF: Open reduction and internal fixation 


\section{References}

1. Mundinger GS, Dorafshar AH, Gilson MM, et al. Analysis of radiographically confirmed blunt-mechanism facial fractures. J Craniofac Surg 2014;25:321-7.

2. Gomes PP, Passeri LA, Barbosa JR. A 5-year retrospective study of zygomatico-orbital complex and zygomatic arch fractures in Sao Paulo State, Brazil. J Oral Maxillofac Surg 2006;64:63-7.

3. Kiwanuka E, Smith SE, Frates MC, Caterson EJ. Use of high-frequency ultrasound guidance for intraoperative zygomatic arch fracture reduction. J Craniofac Surg 2013;24:2036-8.

4. Yamamoto K, Murakami K, Sugiura T, et al. Clinical analysis of isolated zygomatic arch fractures. J Oral Maxillofac Surg 2007;65:457-61.

5. Hindin DI, Muetterties CE, Mehta C, Boukovalas S, Lee JC, Bradley JP. Treatment of Isolated Zygomatic Arch Fracture: improved Outcomes with External Splinting. Plast Reconstr Surg 2017;139:1162-71.

6. Ozyazgan I, Günay GK, Eskitaş̧̧ioglu T, Ozköse M, Coruh A. A new proposal of classification of zygomatic arch fractures. J Oral Maxillofac Surg 2007;65:462-9.

7. Gündeşlioğlu ÖA, Özen C, Inan I, et al. Closed reduction of zygoma tripod and isolated arch fractures with Volkmann bone hook. Kulak Burun Bogaz Ihtis Derg 2013;23:211-6.

8. Zingg $\mathrm{M}$, Laedrach $\mathrm{K}$, Chen $\mathrm{J}$, et al. Classification and treatment of zygomatic fractures: a review of 1,025 cases. J Oral Maxillofac Surg 1992;50:778-90.
9. Podoshin L, Fradis M. The use of the foley balloon catheter in zygomatic-arch fractures. Br J Oral Surg 1974; 12:246-8.

10. El-Hadidy AM. The use of a Foley catheter in isolated zygomatic arch fractures. Plast Reconstr Surg 2005;116:853-6.

11. Randall DA, Bernstein PE. Epistaxis balloon catheter stabilization of zygomatic arch fractures. Ann Otol Rhinol Laryngol 1996;105:68-9.

12. Mezitis M, Stathopoulos P, Rallis G. Use of a curved mosquito for reducing isolated zygomatic arch fractures. J Craniofac Surg 2010;21:1281-3.

13. Hwang K, Lee SI. Reduction of zygomatic arch fracture using a towel clip. J Craniofac Surg 1999;10:439-41.

14. Baek JE, Chung CM, Hong IP. Reduction of Zygomatic Fractures Using the Carroll-Girard T-bar Screw. Arch Plast Surg 2012;39:556-60.

15. Giudice A, Colangeli W, Cristofaro MG. Percutaneous reduction of an isolated zygomatic fracture using a wire suture. $\mathrm{Br} \mathrm{J}$ Oral Maxillofac Surg 2013;51:201-2.

16. Buhr J, Hürtgen M, Kelm C, Schwemmle K. Tumor dissemination after thoracoscopic resection for lung cancer. J Thorac Cardiovasc Surg 1955;110:855-6.

17. Rainer WG. Cardiac surgery before cardiopulmonary bypass. Perfusion 2003;18:139-44. 